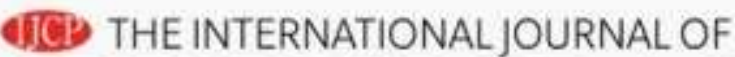 CLINICAL PRACTICE
}

\section{Comparison of characteristics of outpatients with 2009 H1N1 pandemic and seasonal influenza}

\begin{tabular}{|c|c|}
\hline Journal: & International Journal of Clinical Practice \\
\hline Manuscript ID: & IJCP-10-10-0570.R2 \\
\hline Wiley - Manuscript type: & Original Paper \\
\hline $\begin{array}{r}\text { Date Submitted by the } \\
\text { Author: }\end{array}$ & 22-Feb-2011 \\
\hline Complete List of Authors: & $\begin{array}{l}\text { Theocharis, George; SOS Doctors, Athens, Greece } \\
\text { Vouloumanou, Evridiki; Alfa Institute of Biomedical Sciences } \\
\text { (AIBS), Athens, Greece } \\
\text { Barbas, Spyridon; SOS Doctors, Athens, Greece } \\
\text { Spiropoulos, Theodore; SOS Doctors, Athens, Greece } \\
\text { Rafailidis, Petros; Alfa Institute of Biomedical Sciences (AIBS), } \\
\text { Athens, Greece } \\
\text { Falagas, Matthew; Alfa Institute of Biomedical Sciences (AIBS), } \\
\text { Athens, Greece, Department of Medicine, Tufts University School of } \\
\text { Medicine, Boston, Massachusetts, USA. }\end{array}$ \\
\hline Specialty area: & \\
\hline
\end{tabular}

\section{SCHOLARONE" Manuscripts}




\section{Comparison of characteristics of outpatients with 2009 H1N1 pandemic and seasonal influenza}

3

4

5

6 7

8 1. SOS Doctors, Athens, Greece

9 2. Alfa Institute of Biomedical Sciences (AIBS), Athens, Greece

10 3. Department of Medicine, Henry Dunant Hospital, Athens, Greece

11 4. Department of Medicine, Tufts University School of Medicine, Boston,

12 Massachusetts, USA

13
Matthew E. Falagas, MD, MSc, DSc

Alfa Institute of Biomedical Sciences (AIBS),

9 Neapoleos Street, 15123 Marousi, Athens, Greece Tel: +30 (694) 611-0000, Fax: +30 (210) 683-9605

E-mail:m.falagas@aibs.gr
Short title: Characteristics of outpatients with pandemic and seasonal influenza.

Conflict of interest: None

Funding: None

24 Word counts: abstract: 250, text: 2632

25 Number of tables: 2

26 Number of references: 30 


\section{Abstract}

28 Background The latest influenza pandemic intensified the interest in this infection.

29 Objective We aimed to compare the characteristics of outpatients with seasonal and 30 pandemic influenza.

31 Methods We retrospectively reviewed data regarding outpatients that sought medical

32 advice from a network of physicians performing house-call visits at the area of Attica,

33 Greece, that underwent a direct influenza test during the period of seasonal influenza

34 (1/1/2009-1/5/2009), and 2009 H1N1 pandemic influenza period (17/5/2009-

35 15/4/2010).

36 Results A total of 195 and 1317 patients had a direct influenza test during the seasonal 37 and pandemic influenza period, respectively; $50.7 \%$ and $32 \%$ of these patients had a positive test result for influenza, respectively. Viral culture or polymerase chain reaction (PCR) were not implemented. Patients found positive for influenza during the pandemic

40 period, compared to those evaluated during the seasonal period, were younger (mean 41 age \pm SD: $33 \pm 17.2$ vs $38.2 \pm 19.2$, p=0.008), more likely to have no comorbidity $42(62.9 \%$ vs $45.5 \%, \mathrm{p}=0.002)$, had milder clinical manifestations, and were treated with 43 more antibiotics $(38.3 \%$ vs $9.9 \%, \mathrm{p}<0.001)$. However, patients found positive during the seasonal period were treated with more antivirals (oseltamivir: $69.1 \%$ vs $85.7 \%$, $\mathrm{p}=0.006$ ). No difference was observed regarding the need for immediate hospitalization.

47 for influenza during the compared periods.

48 Conclusion Despite the methodological limitations, our findings suggest that patients

49 with pandemic influenza were younger, had milder clinical manifestations, and were

50 less likely to have any kind of comorbidity, compared to patients with seasonal

51 influenza.

Keywords: influenza, oseltamivir, age distribution, diagnosis, primary care

\section{What's known}

56 The $2009 \mathrm{H} 1 \mathrm{~N} 1$ pandemic influenza affected many people worldwide. However, there

57 have been few reports comparing epidemiological, clinical, and treatment characteristics

\section{What's new}


61 Our analysis suggests that patients with pandemic influenza were younger, had milder

62 clinical manifestations, and were less likely to have any kind of comorbidity, compared

63 to patients with seasonal influenza.

64 


\section{Introduction}

The recent influenza pandemic intensified the interest of health organizations, physicians, media, and the public in this infection. Specifically, issues regarding the epidemiological features, diagnosis and treatment of influenza underwent a reevaluation under the perspective of the latest pandemic.

In particular, published reports have suggested that, younger age groups were predominantly affected by the 2009 H1N1 pandemic influenza, ${ }^{1-3}$ whereas, pregnant and obese patients constituted a considerable percentage among more severely afflicted $2009 \mathrm{H} 1 \mathrm{~N} 1$ pandemic influenza cases (including hospitalized and cases admitted in the intensive care unit), as well as among fatalities. ${ }^{2-4}$ With regard to influenza diagnosis, published evidence suggests that the use of direct influenza tests during seasonal influenza periods has been associated with reduced unnecessary antibiotic prescriptions, hospitalizations and laboratory tests. ${ }^{5-7}$ However, the experience of their use during the pandemic period was rather disappointing, as the sensitivities reported in studies evaluating its application in various clinical settings were considered suboptimal. ${ }^{8-10}$ The issue of influenza treatment was also re-evaluated during the pandemic period. Many reports pointed out the benefit of early administration of antiviral treatment to pandemic cases. ${ }^{11-13}$ However, reports on the emergence of pandemic viral strains resistant to oseltamivir had also appeared in the literature. ${ }^{14}$

The aim of this study was to compare the epidemiological, clinical and treatment characteristics of outpatients that sought medical advice from a network of physicians performing house call visits in the area of Attica, Greece, and had a positive direct influenza test, during the $2009 \mathrm{H} 1 \mathrm{~N} 1$ pandemic period, as well as the preceding seasonal (2008-2009) influenza period. Secondly, in a complementary analysis, we aimed to compare the above-mentioned characteristics of all the patients that underwent a direct influenza test in this specific clinical setting, at the respective influenza periods.

\section{Methods}

\section{Patient population}

6 We considered as eligible for inclusion patients that sought medical advice from a 9 network of physicians performing house-call visits at the area of Attica, Greece, who 8 underwent a direct influenza test either during the latest period of seasonal influenza $99(1 / 1 / 2009-1 / 5 / 2009)$, or during the period of 2009 H1N1 pandemic influenza 
100 (17/5/2009-15/4/2010). Since the $1^{\text {st }}$ confirmed case of 2009 H1N1 pandemic influenza

101 in Greece was reported at the $16^{\text {th }}$ of May 2009, we excluded the period 1/5/2009-

$10215 / 5 / 2009$ from our analysis. The direct test was performed at the discretion of the

103 physician performing the house-call visit. The diagnosis was also at the discretion of the 104 physician. Specifically, it was based on the patient's clinical manifestations, along with

105 epidemiological aspects (if any). Diagnostic methods including viral culture and/or PCR

106 were not implemented in our study.

108 The direct influenza test used during both the evaluated periods was the "Influ A\&B

109 Uni-Strip - Dry Swabs (C-1512)" test, manufactured by Coris BioConcept

110 (http://www.corisbio.com). ${ }^{15}$ The "Influ A\&B Uni-Strip - Dry Swabs (C-1512)" test

111 consists of two sides sensitized with a monoclonal antibody specific for Influenza A and

$112 \mathrm{~B}$ and thus allows detection of both influenza A and B, respectively.

114 A subset of the patients in the $1^{\text {st }}$ study period were included in a recent publication

115 focusing on the impact that the introduction of the direct influenza had on the decision

116 making, particularly the prescribing pattern, of the network of SOS Doctors. ${ }^{7}$

\section{Data collection}

119 We retrospectively reviewed the electronic databases of the SOS-Doctors network. We

120 retrieved data regarding the patient's demographic characteristics, types of comorbidity,

121 signs/symptoms that the patients complained for, types of diagnosis, treatment

122 prescribed, as well as the need for immediate hospitalization.

\section{Data analysis}

125 Our primary analysis referred to the comparison regarding the demographic

126 characteristics, types of comorbidity, symptoms, diagnosis, as well as the need for

127 immediate hospitalization were performed between the subgroups of the patients that

128 had a positive direct test for influenza during the evaluated influenza periods. In

129 addition, in a complementary analysis we compared the above-mentioned features for

130 the sub-groups of all the patients that were tested for influenza during the seasonal and

131 pandemic period, respectively. The chi square test was used for all the evaluated

132 dichotomous variables, whereas the Student's t-test or its non-parametric analogue, the

133 Mann-Whitney U test, were used when appropriate for all the evaluated continuous

134 variables. A p-value $<0.05$ was considered as indicative of statistical significance. The 
135 Open Epi software was used to perform the comparisons regarding the outcomes

136 expresses as dichotomous variables, ${ }^{16}$ whereas the SPSS Software was used for the

137 continuous variables.

138

139 Results

140

141 Primary analysis: (patients with a positive direct influenza test result during seasonal

142 vs pandemic influenza period)

143 A total of 99 and 424 patients had a positive test for influenza during the seasonal and

144 pandemic influenza period respectively, constituting the $50.7 \%$ and $32 \%$ of the patients

145 tested for influenza during the respective evaluated influenza periods. No difference was

146 found regarding sex between the compared groups. Patients found positive during the

147 pandemic period were younger compared to patients that were found positive during the

148 seasonal influenza period [mean age \pm standard deviation (SD): $38.2 \pm 19.2$ vs $33 \pm$

149 17.2, $\mathrm{p}=0.008$ ]. Additionally, pediatric patients constituted a significantly higher

150 percentage among patients with a positive test during the pandemic (23\%) period,

151 compared to those with a positive test during the seasonal period (13\%). Moreover,

152 patients that did not have any type of comorbidity constituted a significantly higher

153 percentage among patients with a positive test during the pandemic $(62 \%)$ period,

154 compared to those with a positive test during the seasonal period (45\%). No difference

155 was observed in the comparisons regarding the other evaluated types of comorbidity

156 (detailed data are presented in Table 1).

157

158 Regarding the signs and symptoms for which the evaluated patients complained for,

159 febrile episodes, cough, rigor, nasal congestion/discharge, headache, and

160 myalgia/arthralgia were reported significantly more frequently from patients that were

161 found positive during the seasonal period, whereas the patients that were found positive

162 during the pandemic period complained significantly more frequently for sore throat.

163 No differences were observed in the remaining comparisons (Table1).

165 With regard to treatment characteristics, antivirals (oseltamivir), anticongestants, and

166 anti-asthmatic agents were prescribed significantly more frequently to patients found

167 positive during the seasonal period, whereas antibiotics were prescribed significantly

168 more frequently to patients that were found positive during the pandemic period.

169 Specific data regarding the remaining comparisons of treatment characteristics are 
170 presented in Table 1. Finally, no difference was observed between the compared groups

171 regarding the need for immediate hospitalization.

173 Secondary analysis: (patients that underwent a direct influenza test during seasonal 174 vs pandemic influenza period)

175 A total of 195 and 1317 patients underwent a direct influenza test during the seasonal

176 and pandemic influenza period, respectively. No difference was found regarding sex

177 between the compared groups. Patients tested during the pandemic period were younger

178 compared to patients that were tested during the seasonal influenza period (mean age \pm 179 SD: $41.1 \pm 20.6$ vs $36.7 \pm 19.5$, $\mathrm{p}=0.02$ ). Moreover, pediatric patients were encountered 180 significantly more frequently in the pandemic (17\%) versus the seasonal period $(8 \%)$.

181 Detailed data regarding comorbidity were not available for a considerable percentage of

182 the evaluated patients. In this regard, we were precluded from comparing the types of

183 comorbidity between patients that were tested for influenza during the pandemic and the 184 preceding seasonal influenza period.

186 Febrile episodes, cough, rigor, nasal congestion/discharge, headache, and myalgia/arthralgia were reported significantly more frequently from patients that were tested during the seasonal influenza period compared to those tested during the pandemic influenza period. On the other hand, patients tested during the pandemic

Influenza diagnosis was significantly more frequent in patients tested during seasonal influenza period (50.8\%), compared to those tested during the pandemic period period complained for sore throat significantly more frequently compared to those tested during the seasonal influenza period. No differences were observed regarding the evaluated signs and symptoms between the compared groups (Table 2). (32.2\%), whereas the diagnoses of viral infection, pharyngitis/pharyngotonsillitis, and acute bronchitis were significantly more frequent in patients tested during the pandemic period. No differences were observed regarding the remaining evaluated diagnoses. Detailed data are presented in Table 2. Furthermore, antivirals (oseltamivir), anticongestants, and anti-asthmatics were prescribe significantly more frequently to patients tested during seasonal influenza period, whereas antibiotics were prescribed significantly more frequently to patients tested during the pandemic period. No differences were observed regarding other treatment characteristics (Table 2). No 
204 difference was also observed between the compared groups regarding the need for

205 immediate hospitalization.

206

207 Discussion

208 According to our findings, patients with a positive direct test for influenza during the

2092009 pandemic period were younger and had milder clinical manifestations (as inferred

210 by the signs and symptoms that the patients complained for) compared to those that had

211 a positive test during the seasonal influenza period. Otherwise healthy and pediatric

212 patients were represented by significantly higher percentages among patients found

213 positive for influenza during the pandemic versus the seasonal period. Regarding

214 treatment, antivirals, particularly oseltamivir, were prescribed significantly more

215 frequently to patients found positive for influenza during the seasonal period, whereas

216 antibiotics were prescribed significantly more frequently to patients found positive for

217 influenza during the seasonal period. The above findings were consistent in the

218 complementary analysis regarding the patients that underwent a direct influenza test

219 during the respective influenza periods.

220

221 Our findings regarding the age distribution of patients with pandemic and seasonal

222 influenza are in accordance with another recently published study that focused on the

223 comparison of the epidemiological characteristics of outpatients, as well as inpatients

224 with seasonal and 2009 H1N1 pandemic influenza. Specifically, this study suggested

225 that patients with pandemic influenza were younger compared to patients with seasonal

226 influenza. On the other hand, symptoms including cough, myalgias/arthralgias, and

227 pleuritic chest pain were more frequently encountered among patients with pandemic

228 versus seasonal influenza. ${ }^{17}$ Yet, in our study, cough and myalgia were more common

229 among seasonal compared to pandemic cases. Another study also reported that

230 hospitalized patients with pandemic influenza were younger compared to hospitalized

231 patients with seasonal influenza. ${ }^{18}$

232

233 In addition, with regard to patients' comorbidity, no difference was observed between

234 patients with seasonal and pandemic influenza, with the exception of pregnancy, ${ }^{17}$ in the

235 first of the above-mentioned studies, whereas the other study noted that hospitalized

236 patients with pandemic influenza were less likely to be immunocompromised as

237 opposed to patients with seasonal influenza. ${ }^{18}$ In our study, otherwise healthy patients

238 were encountered more frequently among patients with a positive test result during the 


\section{1}

pandemic period, compared to those found positive during the seasonal influenza period. This observation may reflect the high transmissibility rate of the $2009 \mathrm{H} 1 \mathrm{~N} 1$ pandemic influenza virus. ${ }^{19}$ Another possible explanation may be the fact that younger patients were encountered more frequently among patients with a positive test for pandemic influenza compared to seasonal. Young individuals are more likely to have less comorbidity compared to elderly. Preliminary reports had also suggested that patients with specific types of comorbidity (obese, morbidly obese, pregnant patients) constituted considerable proportions of the confirmed influenza cases and more severely afflicted influenza cases. ${ }^{2,3}$ Yet, we observed no differences regarding any of the evaluated types of comorbidity between pandemic and seasonal influenza cases. The retrospective methodology of our study may potentially account for this observation. Specifically, comorbidity data may have been less likely to be recorded, as opposed to data regarding clinical symptoms and treatment.

Based on the evaluation of the reported clinical signs and symptoms, the patients tested and those with a positive direct test for influenza during the seasonal influenza period, had more severe clinical manifestations compared to patients evaluated during the pandemic period. Indeed, most of the pandemic influenza cases, apart from those with considerable comorbidity that were considered to predispose for more severe disease (including obesity and pregnancy), were cases of mild severity. ${ }^{20,21,22}$ On the contrary, patients tested, as well as those with a positive test complained significantly more frequently for sore throat compared to the respective evaluated patients during the seasonal period. Published evidence suggests that sore throat was one of the symptoms that differentiated the clinical manifestations of seasonal and pandemic influenza infection. Specifically, a recently published large prospective study suggested that the odds of patients that had sore throat to develop pandemic compared to seasonal influenza were 1.4 times as high, relatively to when they didn't have these symptoms. ${ }^{20}$ In our complementary analysis, patients with a positive test constituted a significantly higher percentage among patients tested during the seasonal versus the pandemic influenza period. Many factors may possibly account for this specific observation. Firstly, it should be mentioned that the performance of direct influenza test during the recent influenza pandemic has been questioned. Specifically, the reported sensitivities of such tests were considered as rather low. ${ }^{8,9}$ According to the manufacturer's product information, the sensitivity and specificity of the direct influenza test used in our 
274 study,(namely Influ A\&B Uni-Strip - Dry Swabs (C-1512), for the detection of

275 seasonal influenza A were considerably high (77\% and 100\%, respectively, compared

276 with real time-PCR), and the sensitivity and specificity for the detection of seasonal

277 influenza B were $97 \%$ and $100 \%$ (compared with time-resolved fluoroimmunoassay). ${ }^{15}$

278 However, the available published evidence regarding the diagnostic performance of this

279 specific direct test for pandemic influenza is conflicting. Specifically, the reported

280 specificity of this test is excellent $(100 \%)$, whereas sensitivity is low $(31.7 \%){ }^{23}$

281

282 With regard to treatment characteristics, significantly more antiviral agents were

283 prescribed to patients found positive for influenza during the seasonal compared to the

284 pandemic influenza period. Indeed, an evaluation of preliminary evidence regarding

285 treatment strategies used for cases of pandemic influenza suggested that a considerable

286 percentage of the evaluated patients $(85.0 \%)$ received antibiotic treatment. ${ }^{12}$ However,

287 one should consider the considerable proportion of missing treatment data during the

288 interpretation of the respective findings. Another speculation that may be attempted is

289 the fact that the potential of the emergence of a pandemic influenza strain resistant to

290 the contemporary commercially available antiviral agents may have possibly made

291 physicians reluctant to prescribe these drugs. Indeed, reports on the emergence of

292 pandemic strains resistant to oseltamivir had appeared in the literature during the

293 pandemic period. ${ }^{24-26}$ On the other hand, considering the alarmingly high rates of

294 antibiotic resistance reported for respiratory pathogens, ${ }^{27-29}$ a more conservative

295 therapeutic approach with regard to antibiotic treatment to patients with evidence of

296 viral infections, including influenza, may eventually confer considerable benefit from an

297 individual-patient care, as well from a public health perspective.

299 Specific limitations must be taken into consideration before the extrapolation of the

300 findings of our study. Firstly, our findings refer to a specific clinical setting and to a

301 patient population with specific characteristics. Previously published experience has

302 suggested that patients older than 60 years old constitute a considerable percentage (up

303 to $50 \%$ ) of the target patient population of this specific network of physicians. ${ }^{30}$

304 Selection bias may have also possibly influenced our findings, as the number of patients

305 in the pandemic group by far exceeds the number of the patients in the seasonal group.

306 However, this observation may be considered as expected, given the high demand of

307 relevant medical services during the pandemic period. The intrinsic limitations of a

308 retrospective study design may have also potentially influenced our findings. Finally, 
309 influenza diagnosis was based on the results of a direct influenza test, whereas no other

310 confirmatory methods like viral culture or polymerase chain reaction (PCR) were

311 available in this specific primary-care clinical setting. The rather low sensitivities and

312 specificities of rapid influenza tests used in various clinical settings during the latest

313 influenza pandemic should also be considered in the interpretation of the findings of our 314 study.

316 In conclusion, our findings suggest that patients with a positive direct test result during

317 the pandemic influenza period were younger, had milder clinical manifestations, and

318 were less likely to have any type of comorbidity compared to patients with a positive

319 test result during the evaluated seasonal influenza period. Despite the intrinsic

320 limitations of the retrospective study, our study provides useful comparative data

321 regarding the epidemiological, clinical, as well as treatment characteristics of a

322 considerable number of outpatients evaluated in a primary care setting during the latest

323 pandemic influenza, as well as the preceding seasonal influenza period.

\section{Funding and Acknowledgements}

326 None

\section{Reference list}

329 1. Chowell G, Bertozzi SM, Colchero MA, et al. Severe respiratory disease

330 concurrent with the circulation of H1N1 influenza. N Engl J Med 2009;361:674-9.

331 2. Falagas M, Koletsi P, Baskouta E, Rafailidis P, Dimopoulos G,

332 Karageorgopoulos D. 2009 (H1N1) pandemic influenza: review of the Southern

333 hemisphere experience. . Epidemiol Infect in press 2010.

334 3. Falagas ME, Cholevas NV, Kapaskelis AM, Vouloumanou EK, Michalopoulos

335 A, Rafailidis PI. Epidemiological aspects of 2009 H1N1 influenza: the accumulating

336 experience from the Northern Hemisphere. Eur J Clin Microbiol Infect Dis 2010.

337 4. Plessa E, Diakakis P, Gardelis J, Thirios A, Koletsi P, Falagas ME. Clinical

338 features, risk factors, and complications among pediatric patients with pandemic

339 influenza A (H1N1). Clin Pediatr (Phila) 2010;49:777-81.

340 5. Abanses JC, Dowd MD, Simon SD, Sharma V. Impact of rapid influenza testing

341 at triage on management of febrile infants and young children. Pediatr Emerg Care

$342 \quad 2006 ; 22: 145-9$. 
343 6. Bonner AB, Monroe KW, Talley LI, Klasner AE, Kimberlin DW. Impact of the

344 rapid diagnosis of influenza on physician decision-making and patient management in

345 the pediatric emergency department: results of a randomized, prospective, controlled

346 trial. Pediatrics 2003;112:363-7.

347 7. Theocharis G, Vouloumanou EK, Rafailidis PI, Spiropoulos T, Barbas SG,

348 Falagas ME. Evaluation of a direct test for seasonal influenza in outpatients. Eur J

349 Intern Med 2010;21:434-8.

350 8. Ginocchio CC, Zhang F, Manji R, et al. Evaluation of multiple test methods for

351 the detection of the novel 2009 influenza A (H1N1) during the New York City

352 outbreak. J Clin Virol 2009;45:191-5.

353 9. Hawkes M, Richardson SE, Ipp M, Schuh S, Adachi D, Tran D. Sensitivity of

354 rapid influenza diagnostic testing for swine-origin 2009 a (H1N1) influenza virus in

355 children. Pediatrics 2010;125:e639-44.

356 10. Sandora TJ, Smole SC, Lee GM, Chung S, Williams L, McAdam AJ. Test

357 characteristics of commercial influenza assays for detecting pandemic influenza A

358 (H1N1) in children. Pediatr Infect Dis J 2010;29:261-2.

359 11. Campanini G, Piralla A, Rovida F, et al. First case in Italy of acquired resistance

360 to oseltamivir in an immunocompromised patient with influenza A/H1N1v infection. J

361 Clin Virol 2010;48:220-2.

362 12. Falagas ME, Vouloumanou EK, Baskouta E, Rafailidis PI, Polyzos K, Rello J.

363 Treatment options for 2009 H1N1 influenza: evaluation of the published evidence. Int J

364 Antimicrob Agents 2010;35:421-30.

365 13. Goldstein E, Cowling BJ, O'Hagan JJ, et al. Oseltamivir for treatment and

366 prevention of pandemic influenza A/H1N1 virus infection in households, Milwaukee,

367 2009. BMC Infect Dis 2010;10:211.

368 14. Tramontana AR, George B, Hurt AC, et al. Oseltamivir resistance in adult

369 oncology and hematology patients infected with pandemic (H1N1) 2009 virus,

370 Australia. Emerg Infect Dis 2010;16:1068-75.

371 15. Influ A\&B Uni-Strip Product Information,

372 http://www.corisbio.com/public/product/documents/InfluABEN-v14.pdf.

373 16. Dean, A., K. Sullivan, and M. Soe, OpenEpi: Open Source Epidemiologic

374 Statistics for Public Health, Version 2.2.1. Updated 2008/04/06 [cited 2008/09/18];

375 Available from: www.OpenEpi.com.

376 17. Shiley KT, Nadolski G, Mickus T, Fishman NO, Lautenbach E. Differences in

377 the epidemiological characteristics and clinical outcomes of pandemic (H1N1) 2009 
378 influenza, compared with seasonal influenza. Infect Control Hosp Epidemiol $3792010 ; 31: 676-82$.

380 18. Chang Y-S, van Hal SJ, Spencer PM, Gosbell IB, Collett PW. Comparison of 381 adult patients hospitalised with pandemic (H1N1) 2009 influenza and seasonal 382 influenza during the "PROTECT" phase of the pandemic response. Med J Aust 383 2010;192:90-3.

384 19. Paine S, Mercer GN, Kelly PM, et al. Transmissibility of 2009 pandemic 385 influenza $\mathrm{A}(\mathrm{H} 1 \mathrm{~N} 1)$ in New Zealand: effective reproduction number and influence of 386 age, ethnicity and importations. Euro Surveill 2010;15.

387 20. Tang JW-T, Tambyah PA, Lai FYL, et al. Differing symptom patterns in early 388 pandemic vs seasonal influenza infections. Arch Intern Med 2010;170:861-7.

389 21. Jeong I, Lee CH, Kim DK, Chung HS, Park SW. Mild form of 2009 H1N1

390 influenza infection detected by active surveillance: implications for infection control.

391 Am J Infect Control 2010;38:482-5.

392 22. McLean E, Pebody RG, Campbell C, et al. Pandemic (H1N1) 2009 influenza in 393 the UK: clinical and epidemiological findings from the first few hundred (FF100) cases. 394 Epidemiol Infect 2010;138:1531-41.

395 23. Ciblak MA, Kanturvardar M, Asar S, Bozkaya E, Yenen OS, Badur S.

396 Sensitivity of rapid influenza antigen tests in the diagnosis of pandemic (H1N1)2009

397 compared with the standard rRT-PCR technique during the 2009 pandemic in Turkey.

398 Scand J Infect Dis 2010;42:902-5.

399 24. Oseltamivir-resistant 2009 pandemic influenza A (H1N1) virus infection in two 400 summer campers receiving prophylaxis--North Carolina, 2009. MMWR Morb Mortal 401 Wkly Rep 2009;58:969-72.

402 25. Chen H, Cheung CL, Tai H, et al. Oseltamivir-resistant influenza A pandemic 403 (H1N1) 2009 virus, Hong Kong, China. Emerg Infect Dis 2009;15:1970-2.

404 26. Gulland A. First cases of spread of oseltamivir resistant swine flu between 405 patients are reported in Wales. BMJ 2009;339:b4975.

406 27. Falagas ME, Metaxas EI. Tigecycline for the treatment of patients with 407 community-acquired pneumonia requiring hospitalization. Expert Rev Anti Infect Ther $408 \quad 2009 ; 7: 913-23$.

409 28. Falagas ME, Sideri G, Korbila IP, Vouloumanou EK, Papadatos JH, Kafetzis 410 DA. Inhaled colistin for the treatment of tracheobronchitis and pneumonia in critically 411 ill children without cystic fibrosis. Pediatr Pulmonol 2010. 
412 29. Vardakas KZ, Matthaiou DK, Falagas ME. Comparison of community-acquired 413 pneumonia due to methicillin-resistant and methicillin-susceptible Staphylococcus

414 aureus producing the Panton-Valentine leukocidin. Int J Tuberc Lung Dis

$415 \quad 2009 ; 13: 1476-85$.

416 30. Peppas G, Theocharis G, Karveli EA, Falagas ME. An analysis of patient house 417 calls in the area of Attica, Greece. BMC Health Serv Res 2006;6:112. 418

419 


\begin{tabular}{|c|c|c|c|}
\hline & $\begin{array}{c}\text { Patients with a } \\
\text { positive test during } \\
\text { the seasonal } \\
\text { influenza period } \\
(N=99)\end{array}$ & $\begin{array}{l}\text { Patients with a } \\
\text { positive test during } \\
\text { the pandemic } \mathrm{H} 1 \mathrm{~N} 1 \\
\text { influenza period } \\
(\mathrm{N}=424)\end{array}$ & $P$ value \\
\hline \multicolumn{4}{|l|}{ Demographic characteristics } \\
\hline Sex [females] & $45(45.5)$ & $202(47.6)$ & 0.77 \\
\hline Age (Mean \pm SD, years) & $38.2 \pm 19.2$ & $33 \pm 17.2$ & $\mathbf{0 . 0 0 8}$ \\
\hline $\begin{array}{l}\text { Pediatric patients } \\
(<18 \text { years })\end{array}$ & $13(13.1)$ & $96(22.6)$ & 0.044 \\
\hline \multicolumn{4}{|c|}{$\mathbf{n} / \mathbf{N}(\%)$} \\
\hline \multicolumn{4}{|l|}{ Comorbidity } \\
\hline Number of evaluated patients & 99/99 (100) & $393 / 424(92.6)$ & \\
\hline None & $45(45.5)$ & $247(62.9)$ & 0.002 \\
\hline Malignancies & $2(2.0)$ & $9(2.3)$ & $>0.999$ \\
\hline Cardiovascular diseases & $12(12.1)$ & $47(12.0)$ & 0.89 \\
\hline Tuberculosis & $1(1.0)$ & $2(0.5)$ & 0.98 \\
\hline COPD & $2(2.0)$ & $4(1.0)$ & 0.69 \\
\hline Renal insufficiency & 0 & $5(1.3)$ & 0.64 \\
\hline Asthma & $1(1.0)$ & $21(5.3)$ & 0.08 \\
\hline Allergy & 0 & $4(1.0)$ & 0.81 \\
\hline Diabetes mellitus & $2(2.0)$ & $8(2.0)$ & $>0.999$ \\
\hline Lipid disorders & $4(4.0)$ & $3(0.8)$ & 0.07 \\
\hline Thyroid disorders & $5(5.1)$ & $18(4.6)$ & 0.95 \\
\hline Autoimmune diseases & 0 & $3(0.8)$ & $>0.999$ \\
\hline Multiple sclerosis & 0 & $1(0.3)$ & $>0.999$ \\
\hline Myoskeletal diseases & $2(2.0)$ & $8(2.0)$ & $>0.999$ \\
\hline Inflammatory bowel diseases & 0 & $1(0.3)$ & $>0.999$ \\
\hline $\begin{array}{l}\text { Gastroesophageal reflux } \\
\text { disease }\end{array}$ & $1(1.0)$ & $2(0.5)$ & 0.98 \\
\hline Sideropenic anemia & $1(1.0)$ & $2(0.5)$ & 0.98 \\
\hline Splenectomy & 0 & $1(0.3)$ & $>0.999$ \\
\hline \multicolumn{4}{|l|}{ Signs/symptoms } \\
\hline Number of evaluated patients & 91/99 (92) & $392 / 424(92.4)$ & \\
\hline Febrile episode & $91(100)$ & $364(92.8)$ & 0.017 \\
\hline Sore throat & $16(17.6)$ & $128(32.7)$ & 0.007 \\
\hline Cough & $81(89.0)$ & $301(76.8)$ & 0.015 \\
\hline Rigor & $15(16.5)$ & $32(8.2)$ & 0.027 \\
\hline Nasal congestion/discharge & $80(87.9)$ & $176(44.9)$ & $<0.001$ \\
\hline Headache & $29(31.8)$ & $44(11.2)$ & $<0.001$ \\
\hline Otalgia & 0 & $4(1.0)$ & 0.86 \\
\hline Fatigue/body aches & $17(18.7)$ & $56(14.3)$ & 0.37 \\
\hline Myalgia/arthralgia & $48(52.7)$ & $119(30.4)$ & $<0.001$ \\
\hline Dyspnea/tachypnea & $1(1.1)$ & $20(5.1)$ & 0.14 \\
\hline Thoracic pain & 0 & $2(0.5)$ & $>0.999$ \\
\hline Nausea/vomiting & $4(4.4)$ & $24(6.1)$ & 0.73 \\
\hline Diarrhea/abdominal pain & 0 & $8(2.0)$ & 0.37 \\
\hline $\begin{array}{l}\text { Dizziness/loss of } \\
\text { consciousness }\end{array}$ & $1(1.1)$ & $4(1.0)$ & $>0.999$ \\
\hline \multicolumn{4}{|l|}{ Treatment } \\
\hline Number of evaluated patients & 91/99 (92) & $324 / 424(76.4)$ & \\
\hline Antivirals (oseltamivir) & $78(85.7)$ & $224(69.1)$ & 0.006 \\
\hline Analgesics & $10(11.0)$ & $29(9.0)$ & 0.7 \\
\hline Anti-cough drugs & $16(17.6)$ & $42(13.0)$ & 0.34 \\
\hline Antibiotics & $9(9.9)$ & $124(38.3)$ & $<0.001$ \\
\hline Anticongestants & $19(20.9)$ & $16(4.9)$ & $<0.001$ \\
\hline Antihistamines & $12(13.2)$ & $24(7.4)$ & 0.13 \\
\hline NSAIDs & $2(2.2)$ & $11(3.4)$ & 0.86 \\
\hline
\end{tabular}


Corticosteroids

Corticosteroids $+\beta 2$ agonist

Anti-asthmatics

Other*

\section{Hospitalization}

Number of evaluated patients

Yes

$\begin{array}{ccc}1(1.1) & 1(0.3) & 0.78 \\ 5(5.5) & 15(4.6) & 0.91 \\ 15(16.5) & 12(3.7) & <\mathbf{0 . 0 0 1} \\ 11(12.1) & 11(3.4) & \mathbf{0 . 0 0 3} \\ & & \\ 99 / 99(100) & 424 / 424(100) & 0.65 \\ 1 / 99(1.0) & 10 / 424(2.4) & \end{array}$

0.78

0.91

$<0.001$

0.65

ABbreviations: SD: standard deviation, COPD: chronic obstructive pulmonary disease, NR: notA280rted, NA: non-applicable.

$42 \beta$ value: Sig. (2-tailed) for Student's t-test.

42 Hhcluding: anti-emetics, gastro-protective agents, B-blockers, oral antiseptics, probiotics, antifungals. 425The denominators refer to the respective numbers of the tested pediatric patients. 


\begin{tabular}{|c|c|c|c|}
\hline & $\begin{array}{l}\text { Patients tested } \\
\text { during the seasonal } \\
\text { influenza period } \\
(\mathrm{N}=195)\end{array}$ & $\begin{array}{l}\text { Patients tested during } \\
\text { the pandemic H1N1 } \\
\text { influenza period } \\
(\mathrm{N}=1317)\end{array}$ & $P$ value \\
\hline \multicolumn{4}{|l|}{ Demographic characteristics } \\
\hline Sex [females] & $91(46.7)$ & $640(48.6)$ & 0.67 \\
\hline Age (Mean, \pm SD, years) & $41.1 \pm 20.6$ & $36.7 \pm 19.5$ & $0.02^{\dagger+}$ \\
\hline $\begin{array}{l}\text { Pediatric patients } \\
(<18 \text { years })\end{array}$ & $16(8.2)$ & $219(16.6)$ & 0.003 \\
\hline \multicolumn{4}{|c|}{$\mathbf{n} / \mathbf{N}(\%)$} \\
\hline \multicolumn{4}{|l|}{ Signs/symptoms } \\
\hline Number of evaluated patients & $182 / 195(93.3)$ & $1213 / 1317(92.1)$ & \\
\hline Febrile episode & $180(98.9)$ & $1047(86.3)$ & $<0.001$ \\
\hline Sore throat & $35(19.2)$ & $395(32.6)$ & $<0.001$ \\
\hline Cough & $144(79.1)$ & $790(65.1)$ & $<0.001$ \\
\hline Rigor & $24(13.2)$ & $76(6.3)$ & 0.001 \\
\hline Nasal congestion/discharge & $133(73.1)$ & $326(26.9)$ & $<0.001$ \\
\hline Headache & $54(29.7)$ & $128(10.6)$ & $<0.001$ \\
\hline Otalgia & $1(0.5)$ & $7(0.6)$ & $>0.999$ \\
\hline Asthmatic crisis & 0 & $1(0.08)$ & $>0.999$ \\
\hline Fatigue/body aches & $40(22.0)$ & $206(17.0)$ & 0.12 \\
\hline Myalgia/arthralgia & $101(55.5)$ & $310(25.6)$ & $<0.001$ \\
\hline Dyspnea/tachypnea & $4(2.2)$ & $43(3.5)$ & 0.49 \\
\hline Thoracic pain & $1(0.5)$ & $6(0.5)$ & $>0.999$ \\
\hline Nausea/vomiting & $16(8.8)$ & $77(6.3)$ & 0.28 \\
\hline Diarrhea/abdominal pain & $2(1.1)$ & $30(2.5)$ & 0.38 \\
\hline $\begin{array}{l}\text { Dizziness/loss of } \\
\text { consciousness }\end{array}$ & $1(0.5)$ & $11(0.9)$ & $>0.999$ \\
\hline \multicolumn{4}{|l|}{ Treatment } \\
\hline Number of evaluated patients & $164 / 195(84.1)$ & $839 / 1317(63.7)$ & \\
\hline Antivirals (oseltamivir) & $80(48.8)$ & $240(28.6)$ & $<0.001$ \\
\hline Analgesics & $29(17.7)$ & $107(12.8)$ & 0.12 \\
\hline Anti-cough drugs & $42(25.6)$ & $175(20.9)$ & 0.21 \\
\hline Antibiotics & $52(31.7)$ & $464(55.3)$ & $<0.001$ \\
\hline Anticongestants & $32(19.5)$ & $69(8.2)$ & $<0.001$ \\
\hline Antihistamines & $21(12.8)$ & $67(8.0)$ & 0.06 \\
\hline NSAIDs & $10(6.1)$ & $43(5.1)$ & 0.75 \\
\hline Corticosteroids & $2(1.2)$ & $2(0.2)$ & 0.25 \\
\hline Corticosteroids $+\beta 2$ agonist & $7(4.3)$ & $42(5.0)$ & 0.84 \\
\hline Anti-asthmatics & $29(17.7)$ & $74(8.8)$ & 0.001 \\
\hline Other $^{*}$ & $28(17.1)$ & $93(11.1)$ & 0.043 \\
\hline \multicolumn{4}{|l|}{ Hospitalization } \\
\hline Number of evaluated patients & $195 / 195(100)$ & $1317 / 1317(100)$ & \\
\hline Yes & $4(2.1)$ & $19(1.4)$ & 0.39 \\
\hline
\end{tabular}

ABBreviations: SD: standard deviation, NR: not-reported, NA: non-applicable.

42.8p value: Asymp. Sig. (2-tailed) for Mann-Whitney U test.

42Ancluding: anti-emetics, gastroprotective agents, B-blockers, oral antiseptics, probiotics, antifungals 430 